\title{
TENDÊNCIAS DA DESIGUALDADE SALARIAL NA REGIÃO \\ METROPOLITANA DE PORTO ALEGRE: UMA ABORDAGEM METODOLÓGICA QUANTITATIVA ${ }^{1}$
}

\author{
TRENDS IN WAGE INEQUALITY IN THE METROPOLITAN AREA OF PORTO \\ ALEGRE: A METHODOLOGICAL QUANTITATIVE APPROACH
}

Raul Luís Assumpção Bastos²

\section{RESUMO}

O objetivo deste artigo é o de analisar, por meio de uma metodologia quantitativa, a evolução da desigualdade salarial na Região Metropolitana de Porto Alegre no período 1995-2017. De acordo com o que é nele mostrado, o Desvio Médio Logarítmico (MLD) dos salários-hora reais de homens e mulheres atingiu o seu nível máximo em 2000, e o mínimo, em 2017. Em 2017, sete dos oito subgrupos originários da sobreposição dos recortes de gênero e escolaridade haviam registrado redução da desigualdade salarial em relação a 1995 , sendo exceção o de homens com escolaridade superior completa. A decomposição do MLD revelou que o componente intergrupos representa uma proporção expressiva da desigualdade salarial total, o que confirmou a importância dos recortes de gênero e escolaridade na sua determinação. Como esse componente se reduziu em ritmo menos intenso do que o intragrupos, ele ampliou o seu peso relativo na desigualdade salarial total.

Palavras-chave: desigualdade salarial, medição da desigualdade, decomposição da desigualdade, mercado de trabalho metropolitano.

\begin{abstract}
The objective of this article is to analyze, through a quantitative methodology, the evolution of wage inequality in the Metropolitan Area of Porto Alegre, Brazil, in the period 1995-2017. According to what is shown in the article, the Mean Logarithmic Deviation (MLD) of real hourly wages of men and women reached its maximum level in 2000, and the lowest, in 2017. In 2017, seven of the eight subgroups originating from the overlapping of the gender and education had registered a reduction of the wage inequality in relation to 1995, except for men with complete college education. The MLD decomposition revealed that the between-group component represents an expressive proportion of total wage inequality, which confirmed the importance of gender and schooling demographic characteristics in its determination. As this component declined at a slower pace than the within-group, it increased its relative weight in total wage inequality.
\end{abstract}

Keywords: wage inequality, inequality measurement, inequality decomposition, metropolitan labor market.

Classificação JEL: J01; J31

\footnotetext{
1 O autor gostaria de agradecer as críticas e as sugestões dos Editores e dos Pareceristas da Revista da ABET ao artigo, as quais permitiram aprimorá-lo. Erros e omissões por acaso remanescentes no artigo são de sua inteira responsabilidade.

2 Doutor em Ciências Econômicas pelo Instituto de Economia da UFRJ.

Economista do Departamento de Economia e Estatística, SPGG/RS

- E-mail: rlassumpcaobastos@gmail.com.
} 


\section{INTRODUÇÃO}

O objetivo deste artigo é o de analisar, por meio de uma metodologia quantitativa, a desigualdade salarial na Região Metropolitana de Porto Alegre (RMPA) no período que se estende de 1995 a 2017. A base de dados utilizada no trabalho é a da Pesquisa de Emprego e Desemprego ${ }^{3}$ na RMPA (PED-RMPA), a única que permite a cobertura de todo o período acima delimitado. ${ }^{4}$

Por ser um período relativamente longo, ele acabou comportando conjunturas macroeconômicas muito distintas. Após a estabilização monetária de 1994, ocorreu uma melhora considerável nos rendimentos do trabalho, até 1996 (Fligenspan, 2008). Em um ambiente que combinava baixo crescimento econômico, abertura comercial e reestruturação produtiva, a partir 1997 houve um grande aumento do desemprego e um processo de redução dos rendimentos do trabalho, intensificando a precarização do mercado de trabalho (COUTINHO et al., 1999; Toni, 2007). De 2004 até 2010, em uma conjuntura macroeconômica mais favorável, de maior crescimento do produto e, também, de avanço nas políticas sociais, a tendência foi a de ampliação do emprego formal, redução do desemprego e de recuperação dos rendimentos do trabalho (CARDOSO Jr., 2007; KREIN et al., 2013). O período 2011-2014 foi de baixo ritmo de crescimento econômico, mas com redução do desemprego e aumento dos rendimentos do trabalho, ainda que este último se mostrasse menos vigoroso. Já o período final de cobertura deste estudo compreende uma grave crise econômica, em 2015 e 2016, com uma elevação acentuada do desemprego (BALTAR e LEONE, 2017) e uma queda abrupta dos rendimentos do trabalho.

O que está acima exposto de forma resumida são aspectos muito gerais do comportamento do mercado de trabalho da RMPA no período 1995-2017. Este artigo está voltado para um tema específico, o da evolução da desigualdade salarial nesta região ao longo de todo o período. Além de apresentar evidências do comportamento da desigualdade salarial agregada, o estudo também a analisará, por meio de metodologia quantitativa, por características sociodemográficas selecionadas, quais sejam, gênero e escolaridade. Isto permitirá enriquecer empiricamente a análise da desigualdade salarial, uma vez que a ela serão incorporadas as desigualdades de gênero e de níveis educacionais no âmbito do mercado de trabalho regional.

As questões que organizam este estudo empírico podem ser assim elencadas: quais foram as principais tendências da desigualdade salarial na RMPA no período 1995-2017? Quais as semelhanças e diferenças na evolução da desigualdade salarial entre homens e mulheres? Ao se sobrepor os recortes de gênero e escolaridade, como evoluiu a desigualdade salarial em cada um dos subgrupos populacionais? Que magnitude da desigualdade salarial agregada é determinada pela desigualdade salarial intergrupos? A sua importância relativa aumentou ou diminuiu ao longo do período de análise? As mudanças na composição do emprego por gênero e escolaridade influenciaram a evolução da desigualdade salarial?

Tendo presente o objetivo e as questões propostas, o artigo foi assim estruturado: após essa breve introdução, a seção 2 apresenta, de forma sucinta, a metodologia de medição da desigualdade salarial adotada no estudo; a seção 3 constitui-se em um panorama da desigualdade salarial total e por gênero na RMPA no período 1995-2017; a seção 4 incorpora a escolaridade à

\footnotetext{
3 Sobre a metodologia da Pesquisa de Emprego e Desemprego, ver SEADE e DIEESE (2009).

4 A Pesquisa de Emprego e Desemprego na RMPA era executada pela Fundação de Economia e Estatística Siegfried Heuser (FEE), em convênio celebrado com a Fundação Gaúcha do Trabalho e Ação Social (FTGAS), Fundação Sistema Estadual de Análise de Dados (SEADE-SP), Departamento Intersindical de Estatística e Estudos Sócio-Econômicos (DIEESE), com o apoio do Ministério do Trabalho e Emprego/Fundo de Amparo ao Trabalhador.
} 
análise da evolução desigualdade salarial no mercado de trabalho regional; e, nas considerações finais, são resumidos os principais resultados empíricos do trabalho e sugeridas possibilidades futuras de continuidade desta investigação.

\section{METODOLOGIA DE MEDIÇÃO DA DESIGUALDADE SALARIAL}

Neste trabalho, adota-se um indicador sumário para medir a desigualdade salarial, o Desvio Médio Logarítmico - doravante, MLD (Mookherjee e Shorrocks, 1982; Hao e Naiman, 2010; Cowell, 2011). ${ }^{5}$ O MLD dos salários-hora reais é obtido por meio da seguinte expressão ${ }^{6}$ :

$$
\mathrm{I}_{0}=\frac{1}{\mathrm{n}} \sum_{\mathrm{i}} \log \left(\frac{\mu}{\mathrm{y}_{\mathrm{i}}}\right)
$$

Nesta expressão, tem-se que:

$\mathrm{n}$ : contingente de empregados;

$\mu$ : salário-hora médio real;

$\mathrm{y}_{\mathrm{i}}$ : salário-hora real do indivíduo $\mathrm{i}$.

Como mostra Cowell (2011), o MLD tem limite zero em uma situação de perfeita igualdade de uma distribuição, e tende ao infinito na situação antagônica.

O MLD tem a propriedade de poder ser decomposto de forma aditiva, em um componente intragrupos e outro intergrupos (Shorrocks, 1980; Mookherjee e Shorrocks, 1982; Elbers et al., 2008). A sua decomposição é assim obtida (Mookherjee e Shorrocks, 1982, p. 889):

$$
\mathrm{I}_{0}=\Sigma_{\mathrm{K}} \mathrm{V}_{\mathrm{K}} \mathrm{I}_{0}^{\mathrm{K}}+\Sigma_{\mathrm{K}} \mathrm{V}_{\mathrm{K}} \log \left(1 / \lambda_{\mathrm{k}}\right)
$$

$\mathrm{Na}$ expressão 2, tem-se que:

$\mathrm{V}_{\mathrm{k}}$ : parcela do emprego do subgrupo k no emprego total;

$\mathrm{I}_{0}^{\mathrm{k}}$ : MLD do subgrupo k; e

$\lambda_{\mathrm{k}}$ : salário-hora médio real relativo do subgrupo $\mathrm{k}$, obtido pela divisão do salário-hora médio real do subgrupo k pelo salário-hora médio real do total de empregados.

$\mathrm{Na}$ expressão (2), em seu lado direito, a desigualdade intragrupos corresponde ao primeiro termo, e a desigualdade intergrupos, ao segundo termo. O componente intragrupos é uma média ponderada dos MLD dos subgrupos, sendo os pesos as parcelas de cada subgrupo no emprego total. Quanto ao componente intergrupos, este é determinado pelas diferenças entre os salários-hora médios reais dos subgrupos (Mookherjee e Shorrocks, 1982, p. 889 e 890).

Para apreender as mudanças intertemporais da desigualdade, Mookherjee e Shorrocks (1982, p. 896 e 897) propõem que a decomposição leve em consideração as alterações na

5 O MLD foi também utilizado por Reis e Barros (1991) para analisar a desigualdade salarial por níveis de educação nas regiões metropolitanas do país no período 1976-1986, com dados da Pesquisa Nacional por Amostra de Domicílios do IBGE.

6 Está-se adaptando o trabalho de Mookherjee e Shorrocks (1982), que trata da desigualdade de renda da população. 
estrutura do emprego de acordo com a característica demográfica de interesse. Para tanto, eles derivam $^{7}$ a seguinte expressão das mudanças no MLD entre os períodos $t$ e $t+1$ :

$$
. \Delta \mathrm{I}_{0} \approx \Sigma_{\mathrm{K}} \overline{\mathrm{V}}_{\mathrm{k}} \Delta \mathrm{I}_{0}^{\mathrm{K}}+\Sigma_{\mathrm{K}} \overline{\mathrm{I}}_{0}^{\mathrm{K}} \Delta \mathrm{v}_{\mathrm{K}}+\Sigma_{\mathrm{K}}\left(\lambda_{\mathrm{K}}-\overline{\log \lambda_{\mathrm{k}}}\right) \Delta \mathrm{v}_{\mathrm{k}}+\Sigma_{\mathrm{k}}\left(\bar{\theta}_{\mathrm{k}}-\overline{\mathrm{V}}_{\mathrm{k}}\right) \Delta \log \mu_{\mathrm{k}} .
$$

Na expressão (3), tem-se que:

$\overline{\mathrm{v}}_{\mathrm{k}}$ : parcela média do subgrupo k no emprego total nos períodos $\mathrm{t}$ e $\mathrm{t}+1$;

$\Delta \mathrm{I}_{0}^{\mathrm{k}}$ : mudança no MLD do subgrupo k entre os períodos t e $\mathrm{t}+1$;

$\overline{\mathrm{I}_{0}^{\mathrm{K}}}:$ MLD médio do subgrupo $\mathrm{k}$ nos períodos $\mathrm{t}$ e $\mathrm{t}+1$;

$\Delta \mathrm{v}_{\mathrm{k}}$ : mudança da parcela do subgrupo k no emprego total entre os períodos $\mathrm{t}$ e $\mathrm{t}+1$;

$\bar{\lambda}_{\mathrm{k}}$ : salário-hora médio real relativo do subgrupo $\mathrm{k}$ nos períodos $\mathrm{t}$ e $\mathrm{t}+1$;

$\bar{\theta}_{\mathrm{k}}$ : parcela salarial média do subgrupo k nos períodos t e $\mathrm{t}+1$; e

$\mu_{\mathrm{k}}$ : salário-hora médio real do subgrupo $\mathrm{k}$.

De acordo com o que mostram Mookherjee e Shorrocks (1982, p. 897), o primeiro termo da expressão (3) corresponde à contribuição do componente intragrupos às mudanças no MLD; o segundo e o terceiro termos, às contribuições das mudanças nas parcelas dos subgrupos no emprego aos componentes intragrupos e intergrupos da desigualdade, respectivamente; e o quarto termo, à contribuição do componente intergrupos às mudanças no MLD. ${ }^{8}$

Para complementar a análise da desigualdade salarial feita com base em um indicador sumário - o MLD -, o trabalho ora desenvolvido também fará uso de medidas de dispersão - as razões $9^{\circ}$ decil $/ 1^{\circ}$ decil, $5^{\circ}$ decil $/ 1^{\circ}$ decil e $9^{\circ}$ decil $/ 5^{\circ}$ decil dos salários-hora reais -, as quais permitem conhecer a evolução da desigualdade em diferentes partes da estrutura salarial.

\section{TENDÊNCIAS DA DESIGUALDADE SALARIAL: ASPECTOS GERAIS}

No que diz respeito à desigualdade salarial total ${ }^{10}$ medida pelo $\mathrm{MLD}^{11}$, sua evolução na RMPA pode ser conhecida por meio do Gráfico $1 .{ }^{12}$ Esse indicador evidencia um processo de redução no início da segunda metade dos anos 1990, atingindo 0,3273 em 1997. Após, o MLD elevou-se, chegando, em 2000, ao ponto máximo de todo o período de análise $(0,3753)$. Verificou-se, a partir de então, uma tendência de redução da desigualdade salarial até 2007, quando o MLD se situou em 0,2915. Depois de uma elevação circunscrita a 2008, o MLD retomou a tendência de queda, até atingir 0,1807 em 2017, que se tornou o menor nível de

\footnotetext{
7 Todos os passos da derivação dessa decomposição das mudanças intertemporais no MLD encontram-se em Mookherjee e Shorrocks (1982, p.896 e 897).

${ }^{8}$ Este quarto termo mede a contribuição das mudanças relativas nos salários-hora médios reais dos subgrupos às mudanças no MLD (Mookherjee e Shorrocks, 1982, p. 897).

9 A respeito do contexto que informa o desempenho do mercado de trabalho no período 1995-2017, ver os trabalhos de Fligenspan (2008), Coutinho et al. (2001), Toni (2007), Cardoso Jr. (2007), Krein et al. (2013) e Baltar e Leone (2017).

${ }^{10}$ Neste estudo, o trabalho assalariado corresponde à agregação dos empregados no setor privado, no setor público e os empregados domésticos mensalistas.

${ }^{11}$ Ao longo deste trabalho, sempre que for feita referência ao MLD, ficará implícito que se trata da desigualdade dos salários-hora reais.

${ }^{12}$ O MLD foi computado no Software R, com o pacote dineq. A respeito dos códigos para a computação dessa medida de desigualdade com o pacote dineq, ver Schulenberg (2018).
} 
desigualdade salarial de todo o período analisado. ${ }^{13}$ É interessante constatar, dentre outros aspectos, a continuidade do processo de redução da desigualdade salarial na conjuntura econômica recessiva, posterior a 2014.

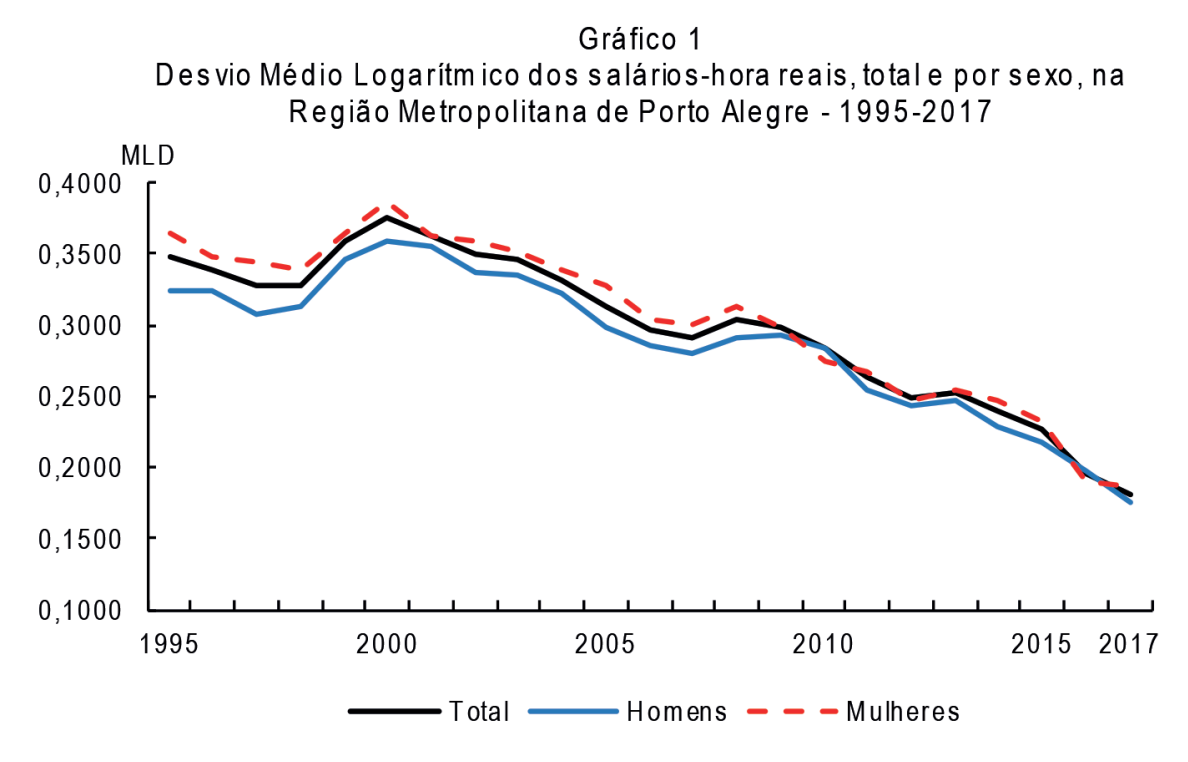

Fonte de dados brutos: PED-RMPA - Convênio FEE, FGTAS, SEADE, DIEESE e apoio MTb/FAT.

Ao segmentar-se o emprego por sexo, é possível perceber que a desigualdade salarial na RMPA foi mais elevada entre as mulheres em praticamente todo o período, com as exceções de 2010 e 2016 (Gráfico 1). Não obstante diferenças localizadas de comportamento, ambos os sexos evidenciavam, em 2017, patamares muito inferiores de desigualdade salarial. De qualquer forma, quando se compara o início e o final do período, pode-se afirmar que ocorreu uma redução da diferença de nível de desigualdade salarial entre os dois subgrupos populacionais: em 1995, o MLD dos homens era de 0,3245, e o das mulheres, de 0,3650; em 2017, esses índices haviam passado para 0,1749 e 0,1859 , respectivamente. Um aspecto que a esse respeito se destaca é a redução da diferença de desigualdade salarial desfavorável às mulheres durante a crise econômica recente, em 2015 e $2016 .^{14}$

Antes de apresentar a desigualdade salarial sob a ótica das medidas de dispersão, é necessário esboçar de forma sucinta a evolução dos decis dos salários-hora reais que são aqui objeto de interesse, o $1^{\circ}$, o $5^{\circ}$ e o $9^{\circ}$ (Gráfico 2). Iniciando pela base da estrutura salarial, podese constatar que o $1^{\circ}$ decil dos salários-hora reais teve um processo de melhora até o ano de 1997 (Gráfico 2A); após, ele ingressou em um período de queda, que perdurou até 2003; de 2004 a 2014 ocorreu um movimento claro de recuperação e de crescimento; na crise econômica, em 2015 e 2016, verificou-se queda; e, em 2017, uma recuperação. Quando se compara 1995 e 2017, constata-se um aumento considerável do $1^{\circ}$ decil dos salários-hora reais: $66,8 \%$ para o total de empregados, 54,4\% para os homens e $85,6 \%$ para as mulheres. ${ }^{15}$ Afora este aspecto, uma vez que o desempenho do $1^{\circ}$ decil dos salários-hora reais foi mais favorável entre as

\footnotetext{
${ }^{13}$ Como uma referência geral, o estudo sobre desigualdade salarial na América Latina de Messina e Silva (2018, capítulo 2) mostra que, no período 1995-2015, o coeficiente de Gini elevou-se até 2002 na região e, após, apresentou uma tendência de queda. No âmbito do país, Cacciamali et al. (2015) apresentam o Índice de Theil dos salários para os anos de 1995, 2005 e 2011, o qual evidencia redução da desigualdade salarial.

${ }^{14}$ Sobre este tema, ver Bastos (2019).

${ }^{15}$ A seguir, esboça-se uma proposta de interpretação do crescimento dos salários reais da base da estrutura salarial na RMPA.
} 
mulheres, este resultado já é um indício de redução da desigualdade salarial de gênero na base da estrutura salarial metropolitana.

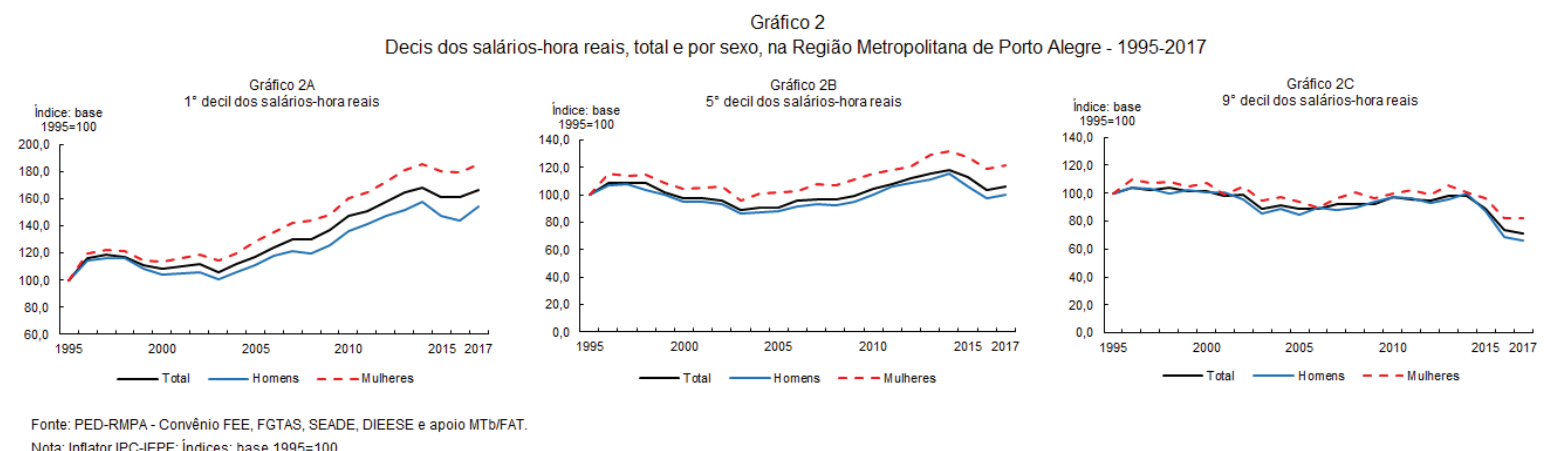

Como foi visto há pouco, os salários da base da estrutura salarial na RMPA tiveram uma trajetória muito distinta daqueles do topo, no período 1995-2017. Enquanto o $1^{\circ}$ decil dos salários-hora reais registrou um crescimento de 66,8\% na comparação de 1995 com 2017, o $9^{\circ}$ decil dos salários-hora reais teve uma queda de $28,8 \%$, nessa mesma referência comparativa. Cabe indagar por que os salários da base da estrutura salarial tiveram este comportamento tão mais favorável, no período. A sugestão de uma resposta a respeito está relacionada com a regulação institucional dos salários, mais precisamente, com o processo de valorização do salário mínimo real (DIEESE, 2015). Neste sentido, o salário-hora mínimo real teve o crescimento expressivo de 110,9\%, no período 1995-2017. Sugere-se que foi este comportamento do salário mínimo que contribuiu para o avanço dos salários reais da base da estrutura salarial da RMPA.

Cabe destacar que esse processo foi mais favorável às mulheres comparativamente aos homens na RMPA. Isto porque a base da estrutura salarial do segmento feminino tem salários em níveis mais baixos do que o dos homens e mais próximos ao salário mínimo. ${ }^{16}$ Assim, o salário-hora mínimo real representava $81,8 \%$ do $1^{\circ}$ decil dos salários-hora reais das mulheres em 1995, e chegou a se situar em 98,8\%, em 2009; no caso dos homens, essas proporções correspondiam a $63,5 \%$ e a $90,7 \%$, nos mesmos anos. Em suma, a interpretação proposta é a de que o processo de valorização do salário mínimo real alavancou o crescimento dos salários da base da estrutura salarial da RMPA, sendo o avanço ainda mais acentuado entre as mulheres.

O centro da estrutura salarial da RMPA evidencia uma trajetória que contém semelhanças, em parte, à da base, conforme descrito acima (Gráfico 2B). Todavia, o processo de perdas do $5^{\circ}$ decil dos salários-hora reais do final dos anos 1990 até 2003 foi mais intenso; o de recuperação e crescimento, de 2004 a 2014, mais modesto; e o de queda na crise econômica, em 2015 e 2016, mais acentuado. Esses aspectos determinaram variações positivas da mediana dos salários-hora reais, na comparação de 1995 e 2017, com as seguintes magnitudes: 6,1\% para o total de empregados, $22,0 \%$ para as mulheres e somente $0,5 \%$ para os homens. Neste sentido, o crescimento do $5^{\circ}$ decil dos salários-hora reais deveu-se, de forma praticamente exclusiva, ao desempenho dos salários reais do segmento feminino.

$\mathrm{Na}$ parte superior da estrutura salarial, o $9^{\circ}$ decil dos salários-hora reais teve um comportamento muito distinto daquele verificado nos salários da sua base e do seu centro (Gráfico 2C). As diferenças que mais se destacam podem ser assim resumidas: o processo de recuperação do $9^{\circ}$ decil dos salários-hora reais, de 2004 a 2014, não repôs todas as perdas

\footnotetext{
${ }^{16}$ Sobre a maior incidência de empregos de baixos salários entre as mulheres e a importância da regulação institucional dos salários, ver Asplund e Persson (2000), Rubery e Grimshaw (2009), Grimshaw (2011) e Fontes et al. (2012).
} 
registradas no período antecedente; e, a partir de $2015^{17}$, esse decil dos salários-hora reais evidenciou uma enorme queda, que se estendeu até 2017. Quando se cotejam os anos de 1995 e 2017 , o $9^{\circ}$ decil dos salários-hora reais evidencia uma retração de $28,8 \%$ para o total de empregados, de 33,5\% para os homens e de 17,5\% para as mulheres. Esses resultados revelam que, ao final do período, no topo da estrutura salarial, havia se reduzido a desigualdade salarial de gênero na região devido, exclusivamente, a perdas salariais mais acentuadas entre os homens.

Apresentada a evolução dos decis dos salários-hora reais selecionados, passa-se à exposição sobre a desigualdade salarial por meio das medidas de dispersão deles resultantes (Gráfico 3). A razão $9^{\circ}$ decil $/ 1^{\circ}$ decil dos salários-hora reais do total de empregados evidencia uma clara tendência de queda ao longo de praticamente todo o período 1995-2017, com uma interrupção circunscrita ao triênio 1998-2000 (Gráfico 3A). O nível máximo de desigualdade salarial revelado por esse indicador ocorreu em 1995 (7,56), e o nível mínimo, em 2017 (3,23) ou seja, uma retração em termos relativos de 57,3\%. Como havia sido mostrado há pouco, esse resultado foi a combinação de desempenhos antagônicos da base e do topo da estrutura salarial metropolitana: positivo no primeiro caso, e negativo, no segundo. Chama também a atenção em concordância com o que havia sido registrado para o MLD -, que a dispersão salarial tenha se encaminhado para o seu piso no contexto de uma crise econômica.

Quando se segmenta o emprego por sexo, percebe-se uma tendência semelhante de queda da razão $9^{\circ}$ decil $/ 1^{\circ}$ decil dos salários-hora reais para homens e mulheres (Gráfico 3A). Uma diferença localizada entre ambos é a de que o período de piora da dispersão salarial, localizado ao final dos anos 1990, ocorreu com defasagem de um ano para os homens. Outros aspectos interessantes são os seguintes: em grande parte do período, essa medida de dispersão salarial foi mais elevada entre os homens, situação distinta à que havia sido vista com o MLD; assinale-se, ainda assim, que em 2017 o indicador se mantinha em nível mais elevado entre as mulheres $(3,39)$ em comparação aos homens $(3,08)$; e, ao final do período, a razão $9^{\circ}$ decil $/ 1^{\circ}$ decil dos salários-hora reais havia atingido o seu menor patamar para ambos os subgrupos populacionais.

A razão $5^{\circ}$ decil $/ 1^{\circ}$ decil dos salários-hora reais do emprego total também evidencia uma tendência de queda ao longo do período 1995-2017, embora não tão intensa quanto àquela verificada entre o topo e a base da estrutura salarial (Gráfico 3B). Caberia recuperar que esse resultado apreende um processo de melhora de ambas as partes da estrutura salarial, uma vez que tanto o centro quanto a base se encontravam em patamares mais elevados em $2017 \mathrm{em}$ comparação a 1995. Assinale-se que houve pioras pontuais desta medida de dispersão salarial, em 1998 e 2011, e de 2012 a 2015 ela manteve relativa estabilidade. Esse indicador de dispersão salarial para o emprego total situou-se no piso do período em $2017(1,45)$.

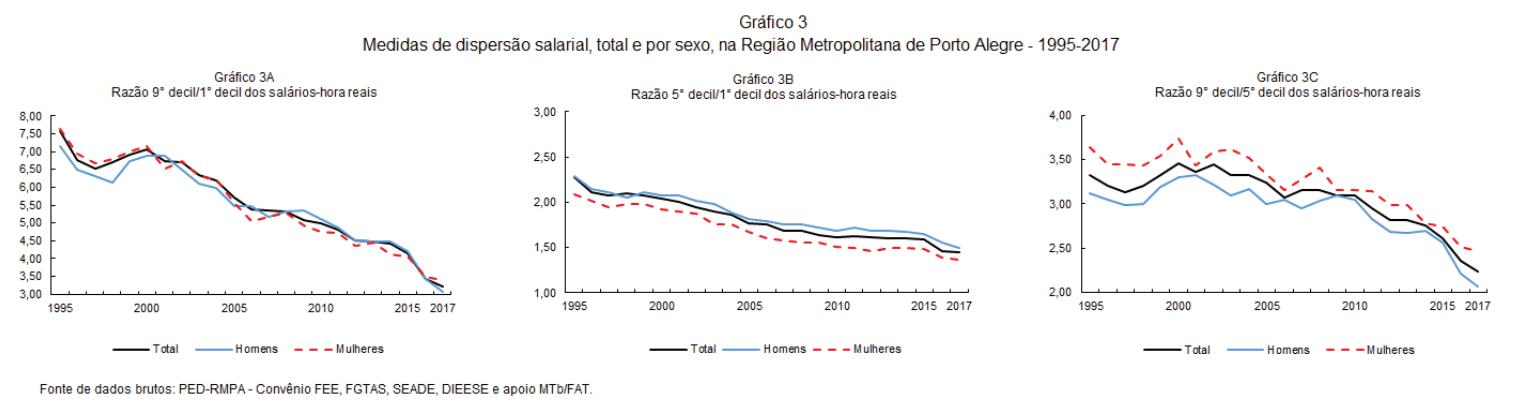

\footnotetext{
${ }^{17}$ No caso específico das mulheres, as perdas salariais já haviam iniciado em 2014.
} 
Para ambos os sexos a razão $5^{\circ}$ decil $/ 1^{\circ}$ dos salários-hora reais registrou uma tendência inequívoca de redução no período que está sendo objeto de análise (Gráfico 3B). Em 2017, essa medida de dispersão salarial tinha atingido o piso da desigualdade de toda a série temporal nos dois segmentos. Afora esses aspectos, o que torna distintivo o comportamento desse indicador em termos comparativos é que ele mostra uma dispersão salarial sistematicamente mais elevada entre os homens em relação às mulheres.

Comparando-se agora o topo e o centro da estrutura salarial da RMPA, a razão $9^{\circ}$ decil $/ 5^{\circ}$ decil dos salários-hora reais do total de empregados registrou queda no início do período de análise e, após, elevou-se, alcançando o ponto máximo da dispersão salarial em $2000(3,46)$ - Gráfico 3C. Foi somente a partir de 2003 que este indicador evidenciou um processo claro de redução, até atingir o piso de todo o período em 2017 (2,23) - ou seja, uma retração de 1/3 em comparação ao início dessa série temporal. Uma qualificação relevante sobre o processo de redução da razão $9^{\circ}$ decil $/ 5^{\circ}$ decil dos salários-hora reais no período posterior a 2003 é a de que, até 2014, ele se deu com melhora dos salários reais em ambas as partes da estrutura salarial, enquanto de 2015 a 2017, em ambas as partes, ocorreram perdas salariais. Neste sentido, o movimento virtuoso de redução da dispersão entre o topo e o centro da estrutura salarial foi circunscrito ao período 2004-2014. ${ }^{18}$

Segmentando-se o emprego por sexo, a razão $9^{\circ}$ decil $/ 5^{\circ}$ decil dos salários-hora reais de homens e mulheres mostra tendências semelhantes ao longo de praticamente toda a série temporal (Gráfico 3C). Esse indicador também revela uma maior dispersão salarial entre as mulheres vis-à-vis aos homens durante todo o período. No ano de 2017 , a razão $9^{\circ}$ decil $/ 5^{\circ}$ decil dos salários-hora reais situava-se no piso da série temporal tanto para homens $(2,07)$ quanto para mulheres $(2,46)$, com uma intensidade de queda, na comparação com 1995, muito próxima, de cerca de $1 / 3$.

\section{DESIGUALDADE SALARIAL: INCORPORANDO A ESCOLARIDADE À ANÁLISE EMPÍRICA DE SUA EVOLUÇÃO}

O objetivo desta seção é o de incorporar a escolaridade à análise empírica da desigualdade salarial. Assumindo-se que esta é um dos atributos que definem as condições de inserção no mercado de trabalho, o propósito será o de investigar quantitativamente a desigualdade salarial por subgrupos de empregados segundo diferentes faixas de escolaridade. ${ }^{19} \mathrm{Em}$ linha com a seção 3 deste trabalho, utilizar-se-á para a medição da desigualdade salarial o MLD, uma vez que este tem a propriedade de poder ser decomposto de forma aditiva em um componente intragrupos e outro intergrupos (Mookherjee e Shorrocks, 1982; Hao e Naiman, 2010; Cowell, 2011). Assim, pretende-se conhecer a evolução da desigualdade salarial no âmbito dos diversos subgrupos de empregados de acordo com as faixas de escolaridade, bem como medir a contribuição de cada um deles à desigualdade salarial agregada.

Esta seção está dividida em duas partes: na subseção 4.1, apresentar-se-á, de forma muito breve, a evolução dos salários-hora médios reais por faixas de escolaridade; e na subseção 4.2, o objeto é a análise da desigualdade salarial, também por faixas de escolaridade.

\footnotetext{
${ }_{18}$ A respeito do processo de retomada da estruturação do mercado de trabalho da RMPA a partir de 2004, com a geração de empregos formais e a redução do desemprego, ver os estudos contidos em Bastos (2013). No âmbito nacional, este processo é analisado nos trabalhos de Cardoso Jr. (2007) e Krein et al. (2013).

19 Para uma visão geral sobre a relação entre educação e desigualdade de rendimentos, ver o estudo de Machin (2009), especialmente as seções 3 e 4.
} 


\subsection{A evolução dos salários reais por faixas de escolaridade}

A apresentação da evolução dos salários-hora médios reais na RMPA será feita de acordo com quatro faixas de escolaridade: fundamental incompleto, fundamental completo, médio completo e superior completo. ${ }^{20}$

Iniciando a exposição pelo segmento com menor nível de educação formal, o comportamento dos salários-hora médio reais de homens e de mulheres com escolaridade fundamental incompleta pode ser sumarizado nos seguintes termos (Gráfico 4A): uma fase inicial de melhora, cuja duração foi até 1997; após, um processo de deterioração, até 2003; uma trajetória de recuperação e crescimento, que se estendeu até 2014; e uma queda durante a crise econômica recente e posterior estabilização. De forma alternativa, por meio da Tabela 1, com as taxas de variação do salário-hora médio real para os diferentes períodos de cobertura deste trabalho, constata-se que o desempenho do segmento feminino com escolaridade fundamental incompleta foi sistematicamente superior ao do masculino, à exceção do período 2015-2017. Neste sentido, quando se compara a variação do salário-hora médio real de 2017 em relação a 1995, o das mulheres havia registrado um crescimento de $31,5 \%$, e o dos homens, uma retração de $1,8 \%$. Com base nesses desempenhos tão distintos, o hiato salarial de gênero (HSG) ${ }^{21}$ no segmento com escolaridade fundamental incompleta se reduziu de 38,0\% em 1995 para 17,1\% em 2017 (Tabela 1). ${ }^{22}$

20 A faixa de escolaridade com fundamental completo inclui indivíduos com médio incompleto; e a com médio completo, indivíduos com superior incompleto.

${ }^{21}$ O hiato salarial de gênero (HSG) no ano t em cada uma das faixas de escolaridade foi calculado da seguinte forma:

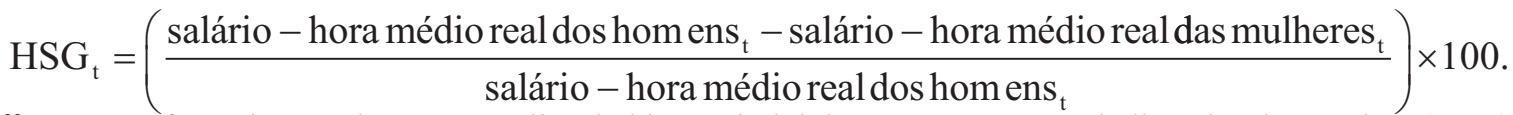

${ }^{22}$ Como referências gerais para a análise do hiato salarial de gênero, ver os trabalhos de Blau e Khan (2008) e de

Gregory (2009). 
Gráfico 4

Salário-hora médio real, por sexo e faixas de escolaridade, na Região Metropolitana de Porto Alegre - 1995-2017

Gráfico $4 \mathrm{~A}$

Salário-hora médio real por sexo dos empregados com escolaridade

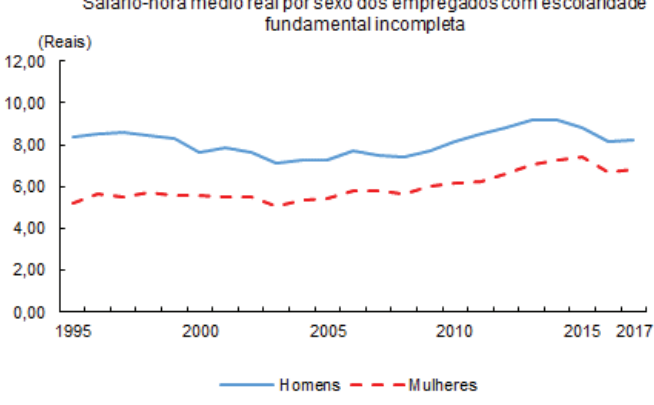

Gráfico 4C

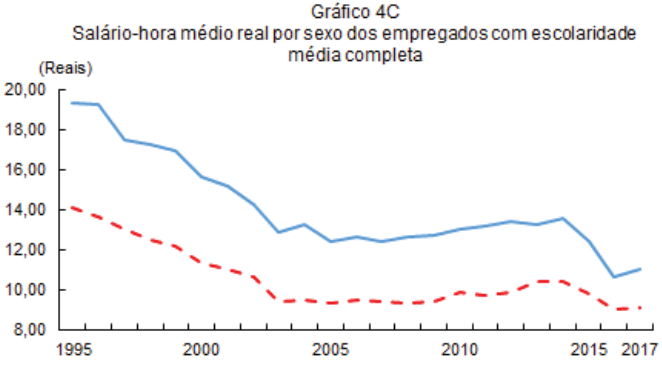

- Homens - - Mulhere
Gráfico 4B

empregados com escolaridade fundamental completa

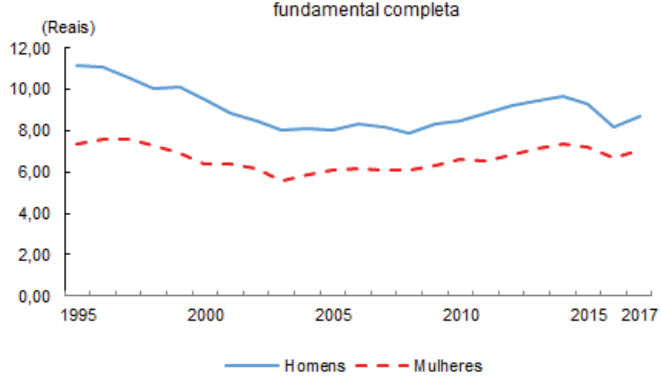

Gráfico 4D
Salário-hora médio real por sexo dos empregados com escolaridade superior completa

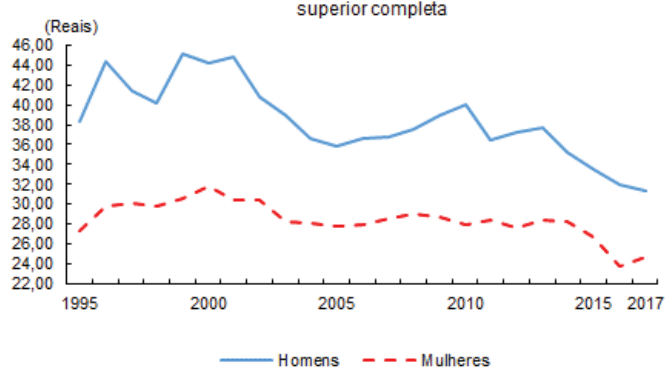

Fonte: PED-RMPA - Convênio FEE, FGTAS, SEADE, DIEESE e apoio MTb/FAT Nota: Inflator IPC-IEPE; valores em reais de dez/2017.

No que diz respeito à faixa de escolaridade com fundamental completo, os aspectos que se destacam foram as perdas mais acentuadas dos salários-hora reais de homens e mulheres até 2003, e uma ausência de plena recuperação dessas perdas no período posterior, que se estendeu até 2014 (Gráfico 4B). De acordo com a periodização proposta pela Tabela 1, o desempenho do salário-hora médio real das mulheres foi, de modo geral, melhor do que o dos homens desta faixa de escolaridade, com exceção do período 2010-2015, em que os ganhos dos últimos foram levemente superiores àqueles obtidos pelas primeiras. Para o período como um todo, o saláriohora médio real dos homens com escolaridade fundamental completa evidenciou uma retração muito intensa $(-21,8 \%)$, e o das mulheres, uma queda mais tênue $(-4,1 \%)$. Tendo por referência desempenhos adversos, mas de intensidades distintas, o HSG do segmento com escolaridade fundamental completa diminuiu de 34,3\% em 1995 para 19,4\% em 2017 (Tabela 1). 
Tabela 1

Taxa de variação dos salários-hora médios reais, por sexo e faixas de escolaridade, e hiato salarial de gênero, na Região Metropolitana de Porto Alegre - 1995 - 2017.(\%)

\begin{tabular}{lcccccc}
\hline \multirow{2}{*}{ Discriminação } & \multicolumn{7}{c}{ Taxa de variação do salário-hora médio real } \\
\cline { 2 - 7 } & $1995-2000$ & $2000-2005$ & $2005-2010$ & $2010-2015$ & $2015-2017$ & $1995-2017$ \\
\hline Fundamental incompleto & $-8,4$ & $-5,5$ & 12,7 & 7,8 & $-6,7$ & $-1,8$ \\
\hline Fundamental completo & $-14,7$ & $-15,4$ & 5,2 & 9,8 & $-6,2$ & $-21,8$ \\
\hline Médio completo & $-19,0$ & $-20,7$ & 4,7 & $-4,8$ & $-11,2$ & $-43,1$ \\
\hline Superior completo & 15,6 & $-19,0$ & 11,7 & $-16,2$ & $-6,7$ & $-18,2$ \\
\hline & \multicolumn{7}{c}{ Homens } \\
\hline Fundamental incompleto & 7,5 & $-3,1$ & 14,6 & 19,9 & $-8,2$ & 31,5 \\
\hline Fundamental comleto & $-12,4$ & $-5,6$ & 9,1 & 9,5 & $-2,9$ & $-4,1$ \\
\hline Médio completo & $-19,6$ & $-17,7$ & 5,6 & $-0,6$ & $-6,9$ & $-35,3$ \\
\hline Superior completo & 16,5 & $-12,7$ & 0,8 & $-4,4$ & $-7,3$ & $-9,2$ \\
\hline Discriminação & & \multicolumn{7}{c}{ Hiato salarial de gênero } & & \\
\cline { 2 - 7 } & 1995 & 2000 & 2005 & 2010 & 2015 & 2017 \\
\hline Fundamental incompleto & 38,0 & 27,3 & 25,4 & 24,1 & 15,7 & 17,1 \\
\hline Fundamental completo & 34,3 & 32,5 & 24,7 & 22,0 & 22,2 & 19,4 \\
\hline Médio completo & 27,2 & 27,7 & 25,0 & 24,3 & 21,0 & 17,2 \\
\hline Superior completo & 28,8 & 28,3 & 22,7 & 30,3 & 20,5 & 21,0 \\
\hline
\end{tabular}

Fonte de dados brutos: PED_RMPA - Convênio FEE, FGTAS, SEADE, DIEESE e apoio MTb/FAT.

Quanto aos empregados da faixa de escolaridade média completa, a queda dos salárioshora médios reais de homens e mulheres ao longo do período 1995-2003 foi muito intensa, e o processo de recuperação, de 2004 a 2014, bastante modesto (Gráfico 4C). Com a redução verificada nos salários-hora médios reais durante a crise econômica, esses atingiram em 2016 os novos pisos das séries temporais para ambos os sexos. Tomando-se o período 1995-2017 como um todo, o salário-hora médio real da faixa de escolaridade média completa teve uma redução muito acentuada entre homens $(-43,1 \%)$ e entre mulheres $(-35,3 \%)$. Neste caso, portanto, a queda do HSG identificada pela Tabela 1, de 27,2\% em 1995 para 17,2\% em 2017, tem como fundamento perdas salariais maiores para os homens em relação às mulheres.

No segmento com escolaridade superior completa, os salários-hora médios reais de homens e mulheres oscilaram na segunda metade dos anos 1990, mas por volta de 1999-2000 haviam atingido os pontos máximos das suas respectivas séries temporais (Gráfico 4D). Após, eles ingressaram em trajetórias de declínio, até alcançarem os seus respectivos pisos em 2005; a intensidade da queda, neste período, foi mais intensa entre os homens. Um movimento de recuperação dos salários-hora médios reais ocorreu entre os homens até 2010, enquanto entre as mulheres esse movimento foi muito tênue. De 2010 até o ano que antecede a crise econômica, o salário-hora médio real dos homens registrou retração, e o das mulheres, pouca variabilidade. Durante a crise econômica, os salários-hora médios reais se retraíram, mas de forma mais acentuada entre as mulheres. Não obstante, ao se cotejar os anos de 1995 e 2017, o saláriohora médio real dos homens com escolaridade superior completa havia tido uma queda de praticamente o dobro $(-18,2 \%)$ da verificada entre as mulheres $(-9,2 \%)$ com o mesmo nível de educação formal. Tendo por referência essas trajetórias dos salários-hora médios reais, o HSG desse segmento de empregados se contraiu de 28,8\% em 1995 para 21,0\% em 2017 (Tabela 
1). Apesar disso, o gap salarial de 2017 era o de maior magnitude entre as diferentes faixas de escolaridade.

\subsection{Desigualdade salarial e escolaridade}

Esta subseção começa com um panorama da desigualdade salarial na RMPA por gênero e faixas de escolaridade no período 1995-2017, para o qual se utilizará o MLD. Posteriormente, serão apresentados os resultados da decomposição da desigualdade salarial agregada, de acordo com esses mesmos atributos.

No subgrupo de empregados com escolaridade fundamental incompleta ocorreram movimentos de redução e de aumento da desigualdade salarial na segunda metade dos anos 1990 e início dos anos 2000 (Gráfico 5A). No caso dos homens, o ponto máximo da desigualdade salarial medida pelo MLD para todo o período de análise foi em $1998(0,1749)$, e para as mulheres, em 2000 (0,1470). A desigualdade salarial evidenciou uma tendência de queda para ambos os sexos desde então, ainda que, no caso feminino, tenha havido um triênio de elevação do MLD (2013-2015). Em 2017, o MLD havia atingido o piso das respectivas séries temporais tanto para homens $(0,0635)$ quanto para mulheres $(0,0394)$.

Por meio da periodização estabelecida na Tabela 2, pode-se constatar que no subgrupo com escolaridade fundamental incompleta predominaram períodos de convergência entre homens e mulheres nas variações do MLD (2000-2005, 2005-2010 e 2015-2017) em relação aos de divergência (1995-2000 e 2010-2015). A intensidade de redução dessa medida de desigualdade salarial no período como um todo foi maior entre as mulheres $(-71,0 \%)$ do que entre os homens $(-66,1 \%)$, e esta se fundamenta nos períodos de convergência entre os sexos das variações do MLD.

Gráfico 5

Desvio Médio Logaritmico dos salários-hora reais, por sexo e faixas de escolaridade, na Região Metropolitana de Porto Alegre - 1995-2017
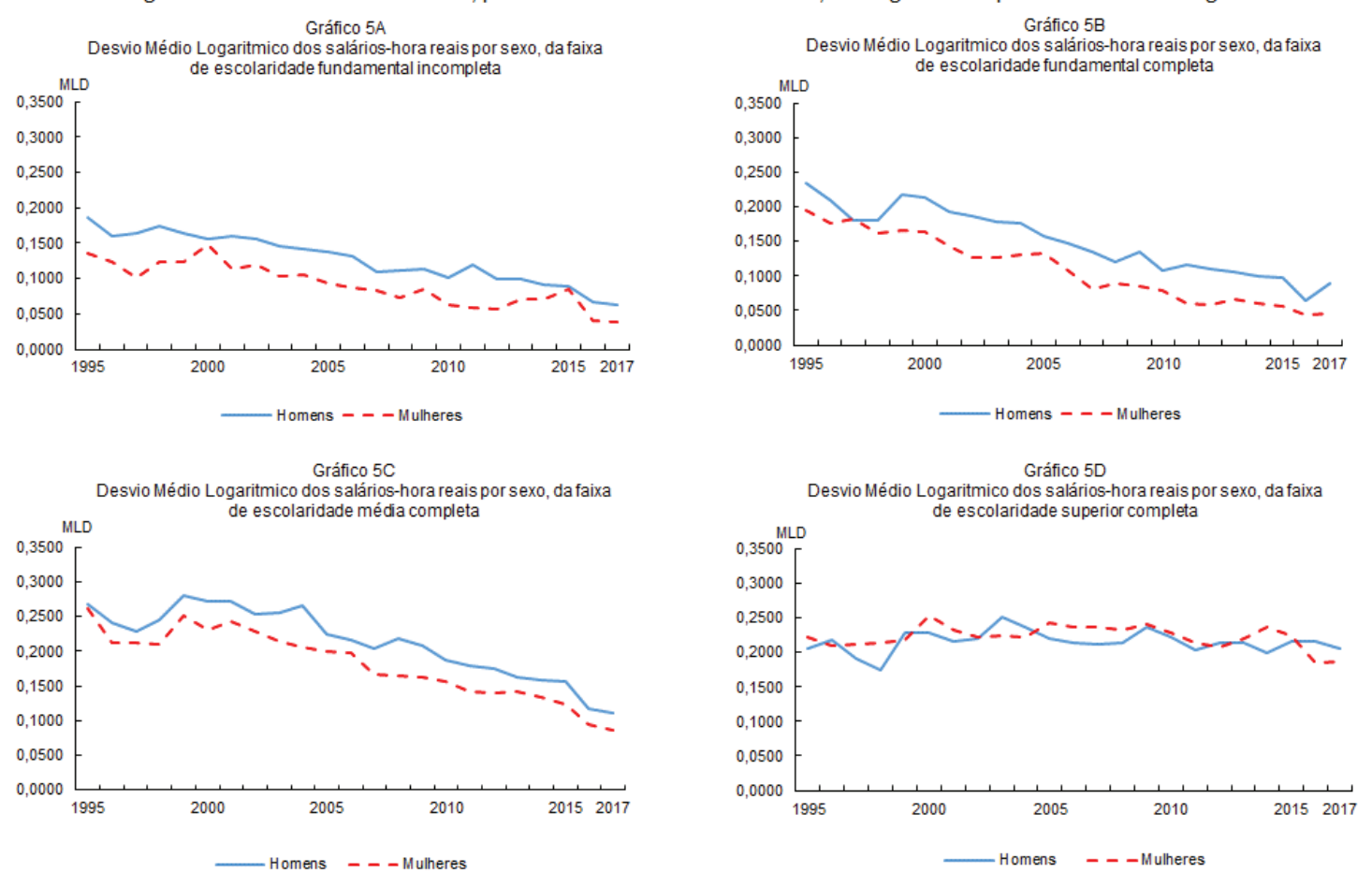

Fonte de dados brutos: PED-RMPA - Convênio FEE, FGTAS, SEADE, DIEESE e apoio MTb/FAT 
Quanto aos empregados com escolaridade fundamental completa, o MLD evidencia oscilações para ambos os sexos na segunda metade dos anos 1990 (Gráfico 5B). O ponto máximo da desigualdade salarial de toda a série temporal foi em 1995 tanto para as mulheres $(0,1947)$ quanto para os homens $(0,2346)$. Nos anos 2000 e 2010 configurou-se uma tendência de queda da desigualdade salarial para ambos os sexos, embora com oscilações do MLD em alguns anos. O ponto mínimo da desigualdade salarial ocorreu em 2016, tendo o MLD se situado em 0,0457 entre as mulheres e em 0,0899 entre os homens.

De acordo com o que pode ser observado na Tabela 2, a periodização nela proposta mostra os movimentos sistemáticos de convergência entre homens e mulheres nas variações do MLD dos empregados com escolaridade fundamental completa. Para toda a série temporal, a retração do MLD foi bem mais intensa entre as mulheres (-76,5\%) em comparação aos homens $(-61,7 \%)$.

Tabela 2

Desvio Médio Logarítmico dos salários-hora reais total, por sexo e faixas de escolaridade e sua decomposição, na Região Metropolitana de Porto Alegre - 1995-2017

\begin{tabular}{|c|c|c|c|c|c|c|c|c|c|c|c|c|}
\hline \multirow[t]{2}{*}{ Discriminação } & \multicolumn{6}{|c|}{ Desvio Médio Logarítmico } & \multicolumn{6}{|c|}{ Taxa da variação do Desvio Médio Logarítmico (\%) } \\
\hline & 1995 & 2000 & 2005 & 2010 & 2015 & 2017 & $1995-2000$ & $2000-2005$ & $2005-2010$ & $2010-2015$ & 2015-2017 & 1995-2017 \\
\hline \multicolumn{13}{|c|}{ Homens } \\
\hline Fundamental incompleto & 0,1871 & 0,1563 & 0,1377 & 0,1003 & 0,0884 & 0,0635 & $-16,5$ & $-11,9$ & $-27,2$ & $-11,9$ & $-28,2$ & $-66,1$ \\
\hline Fundamental completo & 0,2346 & 0,2130 & 0,1572 & 0,1082 & 0,0972 & 0,0899 & $-9,2$ & $-26,2$ & $-31,2$ & $-10,2$ & $-7,5$ & $-61,7$ \\
\hline Médio completo & 0,2675 & 0,2717 & 0,2246 & 0,1878 & 0,1572 & 0,1114 & 1,6 & $-17,3$ & $-16,4$ & $-16,3$ & $-29,1$ & $-58,4$ \\
\hline Superior completo & 0,2050 & 0,2287 & 0,2203 & 0,2215 & 0,2152 & 0,2062 & 11,6 & $-3,7$ & 0,5 & $-2,8$ & $-4,2$ & 0,6 \\
\hline \multicolumn{13}{|c|}{ Mulheres } \\
\hline Fundamental incompleto & 0,1358 & 0,1470 & 0,0927 & 0,0630 & 0,0854 & 0,0394 & 8,2 & $-36,9$ & $-32,0$ & 35,6 & $-53,9$ & $-71,0$ \\
\hline Fundamental completo & 0,1947 & 0,1642 & 0,1320 & 0,0796 & 0,0572 & 0,0457 & $-15,7$ & $-19,6$ & $-39,7$ & $-28,1$ & $-20,1$ & $-76,5$ \\
\hline Médio completo & 0,2622 & 0,2308 & 0,1994 & 0,1561 & 0,1228 & 0,0862 & $-12,0$ & $-13,6$ & $-21,7$ & $-21,3$ & $-29,8$ & $-67,1$ \\
\hline Superior completo & 0,2221 & 0,2532 & 0,2426 & 0,2281 & 0,2237 & 0,1869 & 14,0 & $-4,2$ & $-6,0$ & $-1,9$ & $-16,5$ & $-15,8$ \\
\hline Discriminação & \multicolumn{6}{|c|}{ Desvio Médio Logarítmico total e sua decomposição } & \multicolumn{6}{|c|}{ Taxa de variação do Desvio Médio Logarítmico total e de seus componentes (\%) } \\
\hline & 1995 & 2000 & 2005 & 2010 & 2015 & 2017 & $1995-2000$ & $2000-2005$ & $2005-2010$ & $2010-2015$ & 2015-2017 & $1995-2017$ \\
\hline MLD total & 0,3475 & 0,3753 & 0,3137 & 0,2838 & 0,2270 & 0,1807 & 8,0 & $-16,4$ & $-9,5$ & $-20,0$ & $-20,4$ & $-48,0$ \\
\hline Desigualdade intragrupos & 0,2047 & 0,2021 & 0,1762 & 0,1432 & 0,1272 & 0,0940 & $-1,3$ & $-12,8$ & $-18,7$ & $-11,2$ & $-26,1$ & $-54,1$ \\
\hline Desigualdade Intergrupos & 0,1428 & 0,1732 & 0,1375 & 0,1406 & 0,0998 & 0,0867 & 21,3 & $-20,6$ & 2,3 & $-29,0$ & $-13,1$ & $-39,3$ \\
\hline
\end{tabular}

Fonte de dados brutos: PED-RMPA - Convênio FEE, FGTAS, SEADE, DIEESE e apoio MTb/FAT.

A desigualdade salarial dos empregados com escolaridade média completa também oscilou na segunda metade dos anos 1990, tanto para homens quanto para mulheres (Gráfico 5C). Após, o MLD desse subgrupo entre as mulheres encaminhou-se para uma tendência de redução, enquanto o dos homens manteve relativa estabilidade, até 2004. O nível máximo de desigualdade salarial entre as mulheres ocorreu em 1995 (0,2622), e entre os homens, quatro anos depois, em 1999 (0,2801); já o nível mínimo de desigualdade salarial foi atingido em 2017, para ambos os sexos.

Os períodos de convergência nas variações do MLD entre os sexos dos empregados do subgrupo em foco foram predominantes, sendo exceção o de 1995-2000 (Tabela 2). Em três dos quatro períodos de convergência a desigualdade salarial se reduziu mais para as mulheres. Em linha com este resultado, quando se coteja o primeiro e o último ano da série temporal, se constata que a desigualdade salarial dos empregados com escolaridade média completa teve queda de $67,1 \%$ entre as mulheres, e de $58,4 \%$ entre os homens.

No segmento de empregados com escolaridade superior completa a desigualdade salarial teve um comportamento muito distinto ao das outras faixas de escolaridade. Conforme se constata no Gráfico 5D, não é possível afirmar a ocorrência de uma tendência de redução da desigualdade salarial para homens e para mulheres, a partir de meados dos anos 2000. No caso específico dos homens, após uma queda relevante do MLD em 2004, este se manteve em um patamar em torno de 0,2100, até 2017. É interessante perceber que os pontos mínimos da desigualdade salarial deste subgrupo de empregados ocorreram em anos muito distantes para homens (1998) e mulheres (2016). 
Segundo a periodização contida na Tabela 2, somente no período 2005-2010 verificouse divergência nas variações do MLD de homens e de mulheres com escolaridade superior completa. Devido à redução da desigualdade salarial entre as mulheres durante a crise econômica recente, o que não se verificou entre os homens, elas se encaminharam para valores do MLD inferiores aos dos homens, ao final do período.

Como mostrado anteriormente, o MLD tem a propriedade de poder ser decomposto de forma aditiva - ver a seção 2. Em linha com o que já foi exposto nesta subseção, essa medida de desigualdade salarial foi decomposta com base na constituição de oito subgrupos de empregados, obtidos pela sobreposição dos recortes de gênero e escolaridade. Os resultados desta decomposição do MLD encontram-se na Tabela 2.

Conforme se pode constatar, o componente intergrupos da desigualdade salarial evidenciou aumento na comparação de 1995 com 2000, e o intragrupos, leve redução (Tabela 2). Nos períodos subsequentes houve um processo de redução de ambos os componentes do MLD, sendo exceção 2005-2010, no qual o componente intergrupos teve pequeno acréscimo $(2,3 \%)$. Quando se coteja o primeiro e o último ano da série temporal, constata-se que o componente intragrupos da desigualdade salarial diminuiu mais intensamente $(-54,1 \%)$ do que o intergrupos $(-39,3 \%)$.

A decomposição do MLD permite perceber certa oscilação do peso relativo de seus componentes ao longo do tempo (Gráfico 6). De acordo com os anos selecionados no Gráfíco 6, o componente intergrupos registrou o seu menor peso relativo na desigualdade salarial em 1995 (41,1\%), e o maior, em $2010(49,5 \%) .{ }^{23} \mathrm{Em} \mathrm{2017,} \mathrm{o} \mathrm{peso} \mathrm{relativo} \mathrm{do} \mathrm{componente} \mathrm{intergrupos} \mathrm{na}$ desigualdade salarial era de 48,0\%, superior ao de 1995, uma decorrência deste componente ter se reduzido menos do que o intragrupos nessa base comparativa, conforme destacado há pouco.

Gráfico 6

Peso relativo dos componentes intragrupos e intergrupos do Desvio Médio Logarítmico dos salários-hora reais na Região Metropolitana de Porto Alegre - 1995-2017

$(\%)$

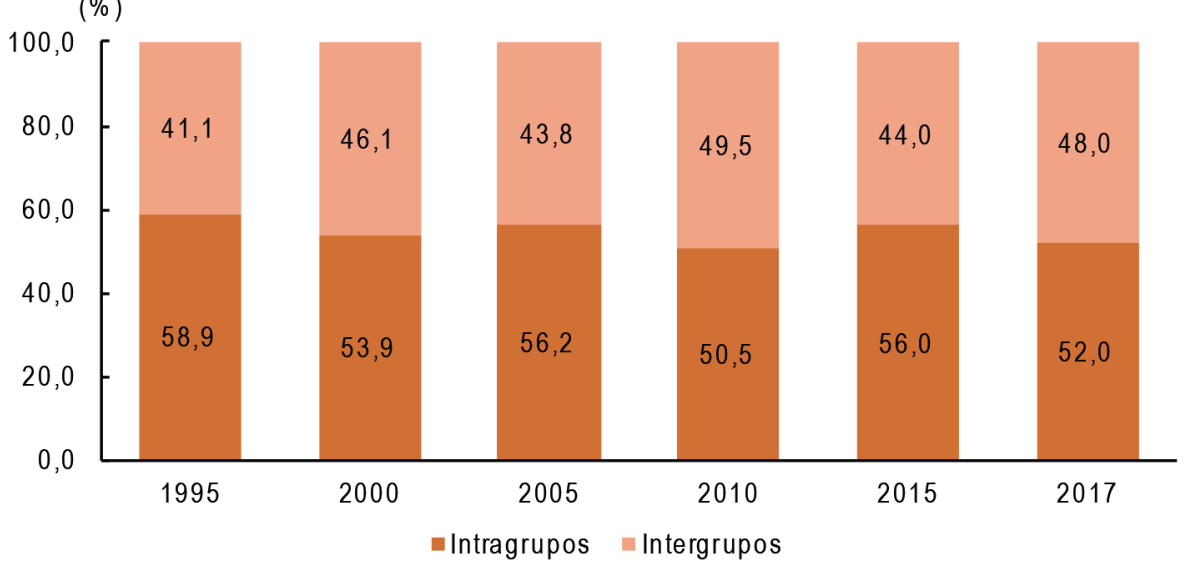

Fonte de dados brutos: PED-RMPA - Convênio FEE, FGTAS, SEADE, DIEESE e apoio MTb/FAT.

Outro aspecto que é de interesse investigar é a contribuição de cada um dos oito subgrupos de empregados ao componente intragrupos do MLD. Para dar conta de forma adequada deste

\footnotetext{
${ }^{23}$ Para uma discussão sobre a importância do componente intergrupos na determinação da desigualdade total, ver Cowell e Jenkins (1995) e Elbers et al. (2008).
} 
aspecto da desigualdade salarial, essas contribuições foram comparadas com as parcelas no emprego total de cada subgrupo, em anos selecionados do período 1995-2017 (Gráfico 7). ${ }^{24}$ No início do período, os subgrupos que mais contribuíram à formação do componente intragrupos da desigualdade salarial eram aqueles com escolaridade fundamental incompleta: homens com $27,5 \%$ e mulheres com $11,9 \%$ (Gráfico 7A). Note-se que essas contribuições, em 1995, eram inferiores às suas parcelas no emprego: $30,0 \%$ no caso dos homens e $18,0 \%$ no das mulheres. Isto se deve ao fato de que os empregados desta faixa de escolaridade eram aqueles que tinham os menores níveis de desigualdade salarial em 1995. Ao final do período, as contribuições destes subgrupos ao componente intragrupos do MLD haviam se reduzido muito para homens (19,9 pontos percentuais), e, com menor intensidade, para mulheres ( 8,7 pontos percentuais). Ao se comparar o primeiro e o último ano do período, como as parcelas dos subgrupos no emprego total tiveram retrações muito expressivas (18,8 pontos percentuais para os homens e 10,3 pontos percentuais para as mulheres), a queda da contribuição de ambos à formação do componente intragrupos da desigualdade salarial foi causada tanto pela redução mais intensa dos respectivos MLD, quanto pela grande perda de peso relativo na estrutura do emprego.

Gráfico 7

Contribuição ao componente intragrupos da desigualdade salarial total e parcela relativa do emprego, por sexo e faixas de escolaridade, na Região Metropolitana de Porto Alegre - 1995-2017
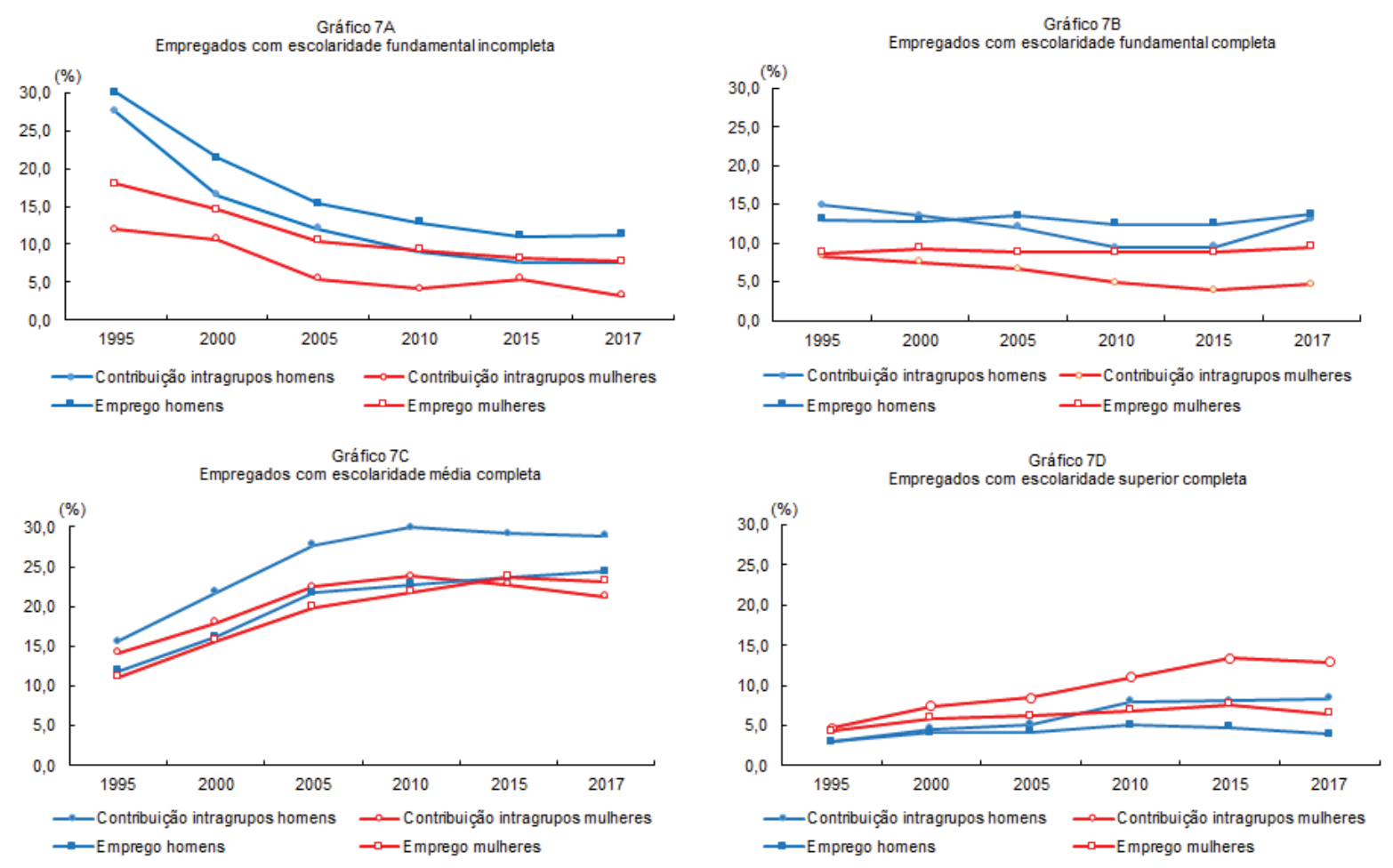

Fonte de dados brutos: PED-RMPA - Convênio FEE, FGTAS, SEADE, DIEESE e apoio MTb/FAT

Os subgrupos que mais ampliaram a sua contribuição à formação do componente intragrupos da desigualdade salarial foram os de empregados com escolaridade média completa (Gráfico 7C). Entre os homens, essa contribuição passou de 15,6\% em 1995 para 28,9\% em 2017 , e entre as mulheres, de $14,2 \%$ para $21,2 \%$, na mesma referência comparativa. Esta mudança é explicada, fundamentalmente, pelos grandes incrementos das parcelas de ambos os sexos no emprego total, o que conferia a esses subgrupos, em 2017, os maiores pesos relativos na estrutura do emprego regional.

\footnotetext{
${ }^{24}$ Conforme se constata na seção 2, o componente intragrupos do MLD é uma média ponderada do MLD de cada um dos subgrupos, sendo os pesos as parcelas no emprego de cada subgrupo.
} 
Os outros subgrupos que ampliaram as suas contribuições ao componente intragrupos da desigualdade salarial foram os de empregados com escolaridade superior completa (Gráfico 7D). No caso dos homens, ao se comparar 1995 e 2017, a contribuição deste segmento havia aumentado de $3,0 \%$ para $8,4 \%$, e no das mulheres, de $4,7 \%$ para $12,9 \%$. Os empregados desta faixa de escolaridade contribuíram à desigualdade salarial acima de suas respectivas parcelas no emprego total, as quais também tiveram um forte acréscimo entre o início e o final do período. Destaque-se, ainda, que o segmento masculino com escolaridade superior completa foi o único que não teve redução do MLD, na comparação de 1995 com 2017.

Quanto aos empregados com escolaridade fundamental completa, eles diminuíram a sua contribuição ao componente intragrupos da desigualdade salarial (Gráfico 7B). A queda foi modesta entre os homens, devido a uma inflexão ascendente da contribuição à desigualdade salarial em 2017. Com exceção dos homens, em 1995 e 2000, em todos os outros anos selecionados ambos os sexos deram contribuições ao componente intragrupos da desigualdade salarial em patamares inferiores as suas parcelas no emprego.

Conforme se constatou no Gráfico 7, ocorreram mudanças consideráveis na estrutura do emprego por gênero e escolaridade na RMPA ao longo do período 1995-2017. ${ }^{25}$ Com base nessa percepção, aplicou-se a decomposição do MLD proposta por Mookherjee e Shorrocks (1982) - expressão 3 da seção 2 deste trabalho -, a qual permite separar a influência dessas mudanças sobre a desigualdade salarial, sendo os seus resultados apresentados na Tabela 3.

\section{Tabela 3}

\section{Contribuição às mudanças do Desvio Médio Logarítmico total dos salários-hora reais na Região Metropolitana de Porto Alegre - 1995-2017}

\begin{tabular}{|c|c|c|c|c|c|}
\hline \multirow{3}{*}{ Período } & \multirow{3}{*}{$\begin{array}{c}\text { Mudanças absolutas no } \\
\text { MLD total }\end{array}$} & \multicolumn{4}{|c|}{ Contribuição às mudanças absolutas no MLD total } \\
\hline & & \multirow{2}{*}{$\begin{array}{l}\text { Desigualdade } \\
\text { intragrupos }\end{array}$} & \multicolumn{2}{|c|}{ Parcelas do emprego } & \multirow{2}{*}{$\begin{array}{c}\text { Desigualdade } \\
\text { intergrupos }\end{array}$} \\
\hline & & & Intragrupos & Intergrupos & \\
\hline $1995-2000$ & 0,0278 & $, 0,0119$ & 0,0091 & 0,0115 & 0,0190 \\
\hline $2000-2005$ & $-0,0516$ & $-0,0370$ & 0,0111 & $-0,0117$ & $-0,0240$ \\
\hline $2005-2010$ & $-0,0299$ & $-0,0373$ & 0,0044 & 0,0107 & $-0,0077$ \\
\hline $2010-2015$ & $-0,0567$ & $-0,0182$ & 0,0022 & $-0,0024$ & $-0,0383$ \\
\hline $2015-2017$ & $-0,0463$ & $-0,0309$ & $-0,0024$ & $-0,0116$ & $-0,0014$ \\
\hline $1995-2017$ & $-0,1667$ & $-0,1353$ & 0,0244 & $-0,0034$ & $-0,0524$ \\
\hline
\end{tabular}

Fonte de dados brutos: PED - RMPA - Convênio FEE, FGTAS, SEADE, DIEESE e apoio MTb/FAT.

Nota: As contribuições às mudanças no MLD total dos períodos correspondem à soma das mudanças interanuais de cada um dos quatro termos da expressão (3).

No período 1995-2000, no acréscimo do MLD, as mudanças nas parcelas do emprego dos componentes intragrupos e intergrupos ${ }^{26}$ contribuíram com $32,7 \%$ e $41,7 \%$, respectivamente, ou seja, essas mudanças influenciaram sobremaneira o aumento da desigualdade salarial (Tabela 3). Nos períodos subsequentes, no qual o MLD evidenciou tendência de queda, o componente determinado pelas mudanças na parcela do emprego intragrupos contribuiu para o aumento

\footnotetext{
${ }^{25}$ No âmbito do país, as mudanças na composição da força de trabalho por faixas de escolaridade estão descritas por Menezes-Filho e Kirschbaum (2015).

${ }^{26}$ Correspondem ao segundo e terceiro termos da decomposição da expressão (3), respectivamente.
} 
da desigualdade salarial, à exceção do período 2015-2017; já o determinado pelas mudanças na parcela do emprego intergrupos reforçou a tendência de redução da desigualdade salarial, à exceção do período 2005-2010. Para o período 1995-2017 como um todo, as mudanças nas parcelas do emprego dos componentes intragrupos e intergrupos deram contribuições antagônicas à desigualdade salarial: o primeiro, isoladamente, implicaria um acréscimo de $14,6 \%$ na mudança absoluta do MLD, e o último, uma redução modesta, de $2,0 \%$. Assim, caso a estrutura do emprego por gênero e faixas de escolaridade tivesse se mantido inalterada, a queda da desigualdade salarial teria sido ainda maior na RMPA.

\section{CONSIDERAÇÕES FINAIS}

Esse artigo teve como objetivo analisar, por meio de uma metodologia quantitativa, a desigualdade salarial na RMPA no período 1995-2017. Como foi nele mostrado, o MLD de homens e mulheres atingiu o seu nível máximo em 2000, e o mínimo, em 2017. Em praticamente todo o período, a estrutura salarial das mulheres foi mais desigual do que a dos homens. Por meio das medidas de dispersão, confirmou-se, como tendência predominante, após o ano 2000, um processo de redução da desigualdade salarial. Uma singularidade encontrada pelo estudo foi a de que a razão $5^{\circ}$ decil $/ 1^{\circ}$ decil dos salários-hora reais era sistematicamente mais elevada entre os homens em comparação às mulheres, o que não se verificou com as medidas de dispersão das outras partes da estrutura salarial.

O trabalho evidenciou que os empregados com escolaridade média completa eram aqueles com maior nível de desigualdade salarial em 1995, para ambos os sexos. Nesse mesmo ano, em posição antagônica, o segmento com menor nível de desigualdade salarial era o de escolaridade fundamental incompleta. Ao final do período de cobertura deste trabalho, sete dos oito subgrupos originários da sobreposição dos atributos gênero e escolaridade haviam registrado redução da desigualdade salarial em relação a 1995, sendo exceção o de homens com escolaridade superior completa, no qual houve aumento.

A decomposição do MLD por gênero e escolaridade revelou que o componente intergrupos representa uma proporção expressiva da desigualdade salarial total na RMPA, jamais inferior a 40,0\%. Como esse componente se reduziu com ritmo menos intenso do que o intragrupos, na comparação de 1995 com 2017, ele ampliou o seu peso relativo na desigualdade salarial, de $41,1 \%$ para $48,0 \%$. No que diz respeito ao componente intragrupos da desigualdade salarial, o segmento que mais contribuiu à sua formação foi o de empregados de ambos os sexos com escolaridade média completa. Em 2017, esse segmento representava cerca de metade do componente intragrupos do MLD.

Como continuidade desta pesquisa sobre a desigualdade salarial, sugerem-se as seguintes possibilidades. A primeira delas seria a de se fazerem análises comparativas entre as regiões metropolitanas do país, com o propósito de se estabelecerem as semelhanças e as diferenças entre elas no que se refere aos níveis e à evolução da desigualdade salarial. A segunda seria a de buscar, por meio do diálogo entre a Economia e a Sociologia do Trabalho, avançar no conhecimento sobre a desigualdade salarial de acordo com diferentes características sociodemográficas, como as adotadas, em termos ainda estritamente empíricos, neste trabalho. 


\section{REFERÊNCIAS}

ASPLUND, R.; PERSSON, I. Low pay: a special affliction of women. In: GREGORY, M.; SALVERDA, W.; BAZEN, S. (eds.). Labour market inequalities: problems and policies of low-wage employment in international perspective. Oxford: OUP, 2000.

BALTAR, P.; LEONE, E. A recessão 2015-2016 e o mercado de trabalho no Brasil. In: Encontro Nacional da Associação Brasileira de Estudos do Trabalho, 15, 2017, Rio de Janeiro. Anais..., Rio de Janeiro: ABET, 2017.

BASTOS, R. (coord.). A retomada do processo de estruturação do mercado de trabalho da Região Metropolitana de Porto Alegre na primeira década do século XXI. Porto Alegre: FEE, 2013.

- Desigualdade salarial na Região Metropolitana de Porto Alegre durante a crise econômica de acordo com os recortes de gênero e raça. Mercado de Trabalho: conjuntura e análise: 25, p. 93-102, 2019.

BLAU, F.; KAHN, L. Women's work and wages. In: DARLAUF, S.; BLUME, L. (eds.). The new Palgrave dictionary of economics. London: Palgrave Macmillan, 2008.

CACCIAMALI, M.; RODGERS, G.; SOUNDARARAJAN, V.; TADEI, F. Wage inequality in Brazil and India and its impact on labour market inequality. New Deli/São Paulo: Institute for Human Development and Cebrap, 2015.

CARDOSO Jr., J. As fontes de recuperação do emprego formal no Brasil e as condições para a sua sustentabilidade temporal. Revista da ABET, VI, p. 87-108, 2007.

COUTINHO, L.; BALTAR, P.; CAMARGO, F. Desempenho industrial e do emprego sob a política de estabilização. In: POSTHUMA, A. (org.). Abertura e ajuste do mercado de trabalho no Brasil: políticas para conciliar os desafios de emprego e competitividade. Brasília: OIT e MTE, 1999.

COWELL, F. Measuring inequality. Oxford: OUP, 2011.

COWELL, F.; JENKINS, S. How much inequality can we explain? A methodology and an application to the United States. The Economic Journal, v. 105, p. 421-430, 1995.

DIEESE. DEPARTAMENTO INTERSINDICAL DE ESTATÍSTICA E ESTUDOS SOCIOECONÔMICOS. Salário mínimo no Brasil: a luta pela valorização do trabalho. São Paulo: LTr, 2015.

ELBERS, C.; LANLOUW, P.; MISTIAEN, J.; ÖZLER, B. Reinterpreting between-group inequality. Journal of Economic Inequality, v. 6, p. 231-245, 2008.

FLIGENSPAN, F. Ganhos e perdas no mercado de trabalho no Real: uma revisão por posição na ocupação. In: DATHEIN, R. (org.). Desenvolvimento econômico brasileiro: contribuições sobre o período pós-1990. Porto Alegre: UFRGS, 2008.

FONTES, A.; PERO, V.; BERG, J. Low-paid employment in Brazil. International Labour Review, v. 151, p. 193-219, 2012.

GREGORY, M. Gender and economic inequality. In: SALVERDA, W.; NOLAN, B.; SMEEDING, T. (eds.). The Oxford handbook of economic inequality. Oxford: OUP, 2009.

GRIMSHAW, D. What do we know about low-wage work and low-wage workers? Geneva: ILO, 2011. Disponível em: http://www.ilo.org/public/libdoc//ilo/2011/111B09_120_engl.pdf. 
Acesso em: 24 mai. 2021.

HAO, L.; NAIMAN, D. Assessing inequality. New York: Sage Publishing, 2010.

KREIN, J.; SANTOS, A.; MORETTO, A. Trabalho no Brasil: evolução recente e desafios. Revista Paranaense de Desenvolvimento, v. 34, p. 27-53, 2013.

MACHIN, S. Education and inequality. In: SALVERDA, W.; NOLAN, B.; SMEEDING, T. (eds.). The Oxford handbook of economic inequality. Oxford: OUP, 2009.

MENEZES-FILHO, N.; KIRSCHBAUM, C. Educação e desigualdade no Brasil. In: ARRETCHE, M. (org.). Trajetórias das desigualdades: como o Brasil mudou nos últimos cinquenta anos. São Paulo: Editora da UNESP, 2015.

MESSINA, J.; SILVA, J. Wage inequality in Latin America: understanding the past to prepare for the future. Washington: The World Bank, 2018.

MOOKHERJEE, D.; SHORROCKS, A. A decomposition analysis of the trend in UK income inequality. The Economic Journal, v. 92, p. 886-902, 1982.

PED. PESQUISA DE EMPREGO E DESEMPREGO. Conceitos, metodologia e operacionalização. São Paulo: SEADE e DIEESE, 2009.

REIS, J.; BARROS, R. Wage inequality and the distribution of education. Journal of Development Economics, v. 36, p. 117-143, 1991.

RUBERY, J.; GRIMSHAW, D. Gender and the minimum wage. Geneva: ILO, 2009.

SCHUlEnBERG, R. Package dineq. Vienna: Comprehensive R Archive Network, 2018. Disponível em: https://cran.r-project.org/web/packages/dineq/index.html. Acesso em: 4 mai 2021.

SHORROCKS, A. The class of additively decomposable inequality measures. Econometrica, v. 48, p. $613-625,1980$.

TONI, M. Precarização do trabalho a partir dos anos 90: reversão de tendência no período recente? In: BASTOS, R. (coord.). Dimensões da precarização do mercado de trabalho na Região Metropolitana de Porto Alegre. Porto Alegre: Convênio PED-RMPA - FEE, FGTAS/ SINE-RS, DIEESE, SEADE-SP, MTE/FAT e apoio PMPA, 2007. 